\title{
华北平原 $\mathrm{BZ}_{2}$ 钻孔沉积物的常量元素地球化学组成与 化学风化
}

姚政权 ${ }^{(12)}$, 肖国桥 ${ }^{(2)}$, 梁美艳 ${ }^{(2)}$

(1) 中国科学院地球环境研究所, 黄土与第四纪地质国家重点实验室, 西安 710075;

(2) 中国科学院研究生院, 北京 100049;

(3) 中国科学院地质与地球物理研究所, 北京 100029

E-mail: yaozq@126.com

2009-02-26 收稿, 2009-05-14 接受

国家自然科学基金(批准号: 40730104)和国家重点基础研究发展计划(编号: 2004CB720203)资助项目

摘要 对华北平原 $\mathrm{BZ}_{2}$ 钻孔沉积物常量元素地球化学研究表明, 该区沉积物来源广泛且处于脱 $\mathrm{Ca}$ 和 $\mathrm{Na}$ 的化学风化初级阶段; 不同化学风化指标均显示晚上新世以来化学风化强度呈波动性减弱, 与内陆黄土高原地区化学风化变化趋势一致, 与冰盖扩张吻合, 显示全球气候变冷对大陆化学风 化强度的控制.

关键词

华北平原

晚上新世

化学风化

冰盖

全球变冷
硅酸盐岩的机械剥蚀和化学风 化作用可通过影响全球碳循环对全 球气候产生影响 ${ }^{[1,2]}$, 因此, 硅酸盐 岩风化剥蚀作用受到学术界普遍关 注 ${ }^{[3-5]}$. 大陆风化产生的碎屑物质通 过河流作用搬运到沉积区保存, 沉 积物的化学风华程度与源区岩性、气 候变化以及之后的搬运和沉积过程 密切相关 ${ }^{[6]}$. 因此, 河流沉积物地球 化学研究对理解大陆风化和全球气 候变化具有重要意义.

华北平原处于东亚季风控制下 的半干旱-半湿润区 ${ }^{[7]}$, 黄河、海河 等河流带来大量碎屑物质在该区堆 积. 由于缺少具有较好年代控制的 长尺度记录, 华北平原晚上新世以 来关于大陆风化的研究较少, 在一 定程度上限制了对本区沉积物风化 与气候变化之间关系的深入理解.
因此, 本文对渤海湾西岸具有系统磁 性地层年代学研究的 $B Z_{2}$ 钻孔 ${ }^{[8]}$ 沉积 物进行了常量元素地球化学研究, 并 与黄土高原的风尘堆积进行对比, 初 步探讨该区化学风化特征及控制因素. $\mathrm{BZ}_{2}$ 钻孔 $\left(117^{\circ} 8^{\prime} \mathrm{E}, 39^{\circ} 2^{\prime} \mathrm{N}\right)$ 位于 渤海湾西岸天津市, 岩芯长度为 $203.6 \mathrm{~m}$, 全孔取芯率为 $89.3 \%$. 这套 沉积粒度总体较细, 以粉砂、粉砂质 黏土为主, 偶尔夹有数层细-粗砂. 沉积学和微体生物证据显示, 钻孔 $\sim 25 \mathrm{~m}$ 以上为受海洋影响的海洋-河 流交互沉积, $25 \mathrm{~m}$ 以下为河流相沉积. 对钻孔中采集的 461 块样品进行系 统热退磁和交变退磁后, 建立的古 地磁极性柱与标准极性年表 ${ }^{[91}$ 对比 结果如图 1 所示, 研究结果表明 $\mathrm{BZ}_{2}$ 钻孔的底界年代为 $3.2 \mathrm{Ma}^{[8]}$. 本 研究中年代标尺基于古地磁极性界
限和释光年代 ${ }^{[10]}$ 线性内插得到. 在表生环境下, 不同常量元素 的减少或富集与风化过程密切相关,

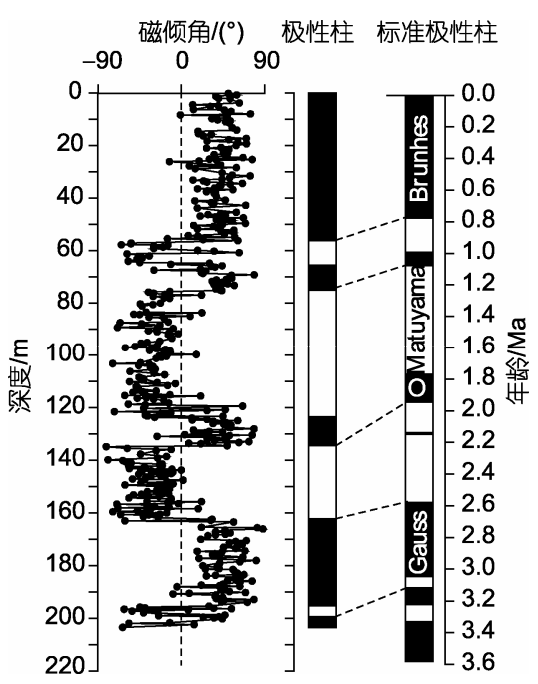

图 $1 \mathrm{BZ}_{2}$ 钻孔磁性地层结果及其与 标准极性年表 ${ }^{[9]}$ 的对比 
因此常量元素地球化学研究可揭示 大陆化学风化变化 [11]. 为此, 我们 对 $\mathrm{BZ}_{2}$ 钻孔中 314 个样品进行常量元 素测试. 为了减小粒度分选 ${ }^{[12]}$ 和次 生碳酸盐对化学组成含量的影响, 我们按照Wei等人 ${ }^{[13]}$ 的方法对样品 进行醋酸淋溶处理并选取酸不溶物 中 $<30 \mu \mathrm{m}$ 的组分进行测试, 测试仪 器为Philips PW4400 X射线菼光光谱 仪. 在测试过程中每测量 30 个样品, 我们测量一次标准样品进行对比检 验, 以确保仪器稳定性, 元素测量误 差小于 $\pm 2 \%$.

Nesbitt等人 ${ }^{[14]}$ 根据元素活动性 顺序将化学风化过程分为早期脱 $\mathrm{Ca}$ 和 $\mathrm{Na}$, 中期脱 $\mathrm{K}$ 和晚期脱 $\mathrm{Si}$ 阶段. $\mathrm{A}-\mathrm{CN}-\mathrm{K}\left(\mathrm{Al}_{2} \mathrm{O}_{3}-\mathrm{CaO} *+\mathrm{Na}_{2} \mathrm{O}-\mathrm{K}_{2} \mathrm{O}\right)$ 三 角图 $(\mathrm{CaO}$ *是指硅酸盐中的 $\mathrm{CaO}$, 下 同)常被用来估测大陆风化趋势 ${ }^{[14]}$. 从 A-CN-K图解(图 2)中可以看出, 所 有样品点在三角图上平行于A-CN边 线, 表明沉积物处于化学风化早期 脱 $\mathrm{Ca}$ 和 $\mathrm{Na}$ 阶段 ${ }^{[14]}$. 样品都集中分布 在上地壳平均组成(UCC)的风化趋 势线上, 反映了 $\mathrm{BZ}_{2}$ 钻孔沉积物的来 源区比较广泛, 并经过充分物

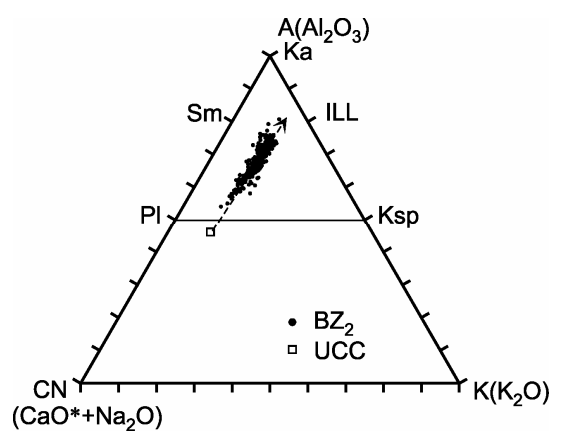

图 $2 \mathrm{BZ}_{2}$ 钻孔沉积物化学组成 A-CN-K 三角模式图

图中箭头代表大陆风化趋势, $\mathrm{Pl}$, 斜长石, Ksp, 钾长石, Sm, 蒙脱石, ILL, 伊利石, Ka, 高岭石; 上地壳平均值(UCC)据文献 [15]

质循环混合 ${ }^{[15]}$. 硅酸盐岩在风化过 程中长石因不稳定而分解, 使风化产 物中铝钾比值增大 ${ }^{[16]}$. 化学风化指数 (CIA)可以很好地定量表示硅酸盐岩 的化学风化强度, 因此常作为一个判 断源区化学风化程度的指标被广泛应 用 $[16 \sim 18]$. 公式表示为: $\mathrm{CIA}=\left[\mathrm{Al}_{2} \mathrm{O}_{3}\right.$ / $\left.\left(\mathrm{Al}_{2} \mathrm{O}_{3}+\mathrm{CaO} *+\mathrm{Na}_{2} \mathrm{O}+\mathrm{K}_{2} \mathrm{O}\right)\right] \times 100$. 由于 $\mathrm{K}, \mathrm{Ca}$ 和 $\mathrm{Na}$ 等元素在化学风化过 程中易从源岩分解出来而被溶液带 走 ${ }^{[14,19]}$, 而 $\mathrm{A} 1$ 和 $\mathrm{Ti}$ 等元素在风化过 程中活动性弱, 几乎被等量地迁
移到碎屑沉积物中去 ${ }^{[11]}$, 因此CIA, $\mathrm{Al} / \mathrm{K}$, 和 $\mathrm{Ti} / \mathrm{Na}$ 等常用来反映沉积物 源区化学风化强度 111,16$]$.

从图 3 可以看出, 晚上新世以来 $\mathrm{BZ}_{2}$ 钻孔沉积物 CIA 值逐渐减小, 在 $\sim 3.2$ Ma CIA 值最高达 80, 进入全新 世 CIA 值降为 $\sim 60$, 其间存在多次波 动(图 3(c)). $\mathrm{Al} / \mathrm{K}$ 和 $\mathrm{Ti} / \mathrm{Na}$ 比值自 3.2 $\mathrm{Ma}$ 以来也逐渐减小(图 3(a)和(b)). 这 些结果表明, 晚上新世以来钻孔沉积 物的化学风化强度逐渐减弱.

影响沉积物 CIA 和其他元素比 值的因素主要有源区化学风化变 化、沉积物搬运过程中沉积分异作 用对矿物组成的影响以及物源变化 [23]. 碎屑物质搬运过程中, 沉积分 异作用引起矿物组成变化会影响沉 积物中元素组成 ${ }^{[24]}$. 由于元素 $\mathrm{Al}, \mathrm{Ti}$, $\mathrm{Ca}, \mathrm{Na}$ 和 $\mathrm{K}$ 主要赋存在沉积物细粒组 分中 ${ }^{[25]}$, 我们通过测试 $<30 \mu \mathrm{m}$ 组分中 元素含量可以减小沉积分异作用的影 响. 同时, $\mathrm{BZ}_{2}$ 钻孔沉积物粒度总体较 细, 以粉砂、粉砂质黏土为主, 因此, 搬运过程中的沉积分异作用对上述元 素比值的影响可能很小.

沉积物物源变化可能也会影响

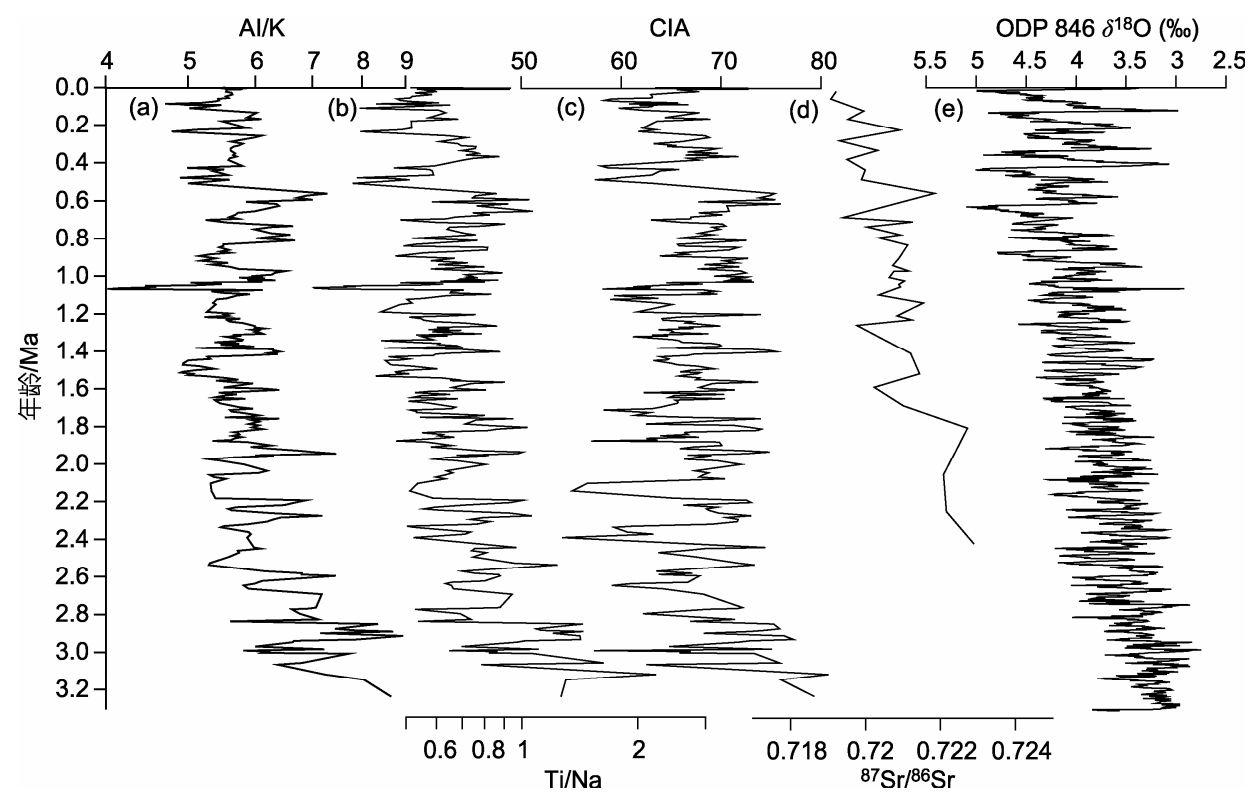

图 $3 \mathrm{BZ}_{2}$ 钻孔 $\mathrm{Al} / \mathrm{K}(\mathrm{a}), \mathrm{Ti} / \mathrm{Na}(\mathrm{b})$ 和 CIA(c), 洛川剖面 ${ }^{87} \mathrm{Sr} /{ }^{86} \mathrm{Sr}$ (d)及与深海氧同位素(e)的对比 (d)的数据来自文献 [28], (e)的数据来自文献 [21, 22] 
$\mathrm{BZ}_{2}$ 钻孔沉积物化学风化强度. 华 北平原主要由黄河、海河和㴒河等 河流多次决口改道、反复泛滥冲淤 形成 ${ }^{[26]}$. 华北和西北地区, 特别是 黄河、海河和㴒河流域是华北平原 沉积物的主要物源供给区 ${ }^{[26,27]}$. 晚 上新世以来青藏高原隆升加剧 [28], 我国西高东低的地貌格局得到进一 步发展, 黄河、海河等河流从华北 和西北地区带来大量碎屑物质在该 区沉积. 在此期间虽然黄河可能多 次决口改道 ${ }^{[29]}$, 但由于其能够在短 期内反复泛滥冲淤, 在 $10^{5} \sim 10^{6}$ 年 时间尺度上, 改道造成物源的可能 变化不会影响本研究中化学风化强 度整体变弱的趋势. 同时, $\mathrm{BZ}_{2}$ 钻孔 沉积化学组成的A-CN-K图(图 2)表 明, 碎屑物质在搬运过程中经历了
高度混合过程, 成份变得相对均一. 因此, 钻孔沉积 CIA和其他化学风 化指标主要反映沉积物源区化学风 化强度变化。

在现代气候条件下, 化学风化 程度主要受控于当地的气温和降水 [30]. 高温和高降水量可以加强化学 风化强度, 而低温和低降水量使化 学风化强度降低 ${ }^{[30]} . \mathrm{BZ}_{2}$ 钻孔沉积 物的地球化学指标显示 3.2 Ma以 来化学风化强度减弱(图 3(a) (c)), 与深海氧同位素指示的冰盖扩张一 致 ${ }^{[21,22]}$ (图 3(e)), 揭示了冰量发展 对华北平原地区冲积物的化学风化 强度具有控制作用. 晚上新世以来 冰盖扩张 $[21,22]$ 导致大陆气候变得 冷干 [31]可能是造成研究区化学风 化强度减弱的重要原因. 华北平原
孢粉研究显示早更新世以来该区逐 渐变冷变干 ${ }^{[27]}$, 支持上面的推论. 洛川黄土-古土壤序列的锶同位素 研究 ${ }^{[201}$ (图 3(d))显示, 2.5 Ma以来 风尘堆积的化学风化强度逐渐减弱, 与本研究结果一致, 冰盖扩张导致 亚洲大陆气候变得冷干是造成黄土 源区化学风化强度减弱的主要原因 [20].

晚上新世以来全球变冷造成 青藏高原侵蚀速率增加 ${ }^{[32]}$, 沉积区 沉积速率普遍增加 ${ }^{[33]}$, 因而可能导 致较多矿物成熟度低的碎屑物质加 入, 造成化学风化强度减弱. 因此, 晚上新世全球变冷导致侵蚀区更多 弱风化物质的加入也可能加剧研究 区 3.2 Ma以来化学风化强度减弱 的趋势.

致谢 天津市地震局陈宇坤博士提供岩芯样品, 与葛俊逸和周金同学进行有益的讨论, 审稿专家提出建设性的意见, 在此一并表示衷心的感谢.

\section{参考文献}

1 Raymo M E, Ruddiman W F. Tectonic forcing of late Cenozoic climate. Nature, 1992, 359: 117-122[doi]

2 Raymo M E. The Himalayas, organic carbon burial, and climate in the Miocene. Paleoceanography, 1994, 9: 399-404[doi]

3 Gaillardet J, Dupre B, Allegre C J. Geochemistry of large river suspended sediments: Silicate weathering or recycling tracer? Geochim Cosmochim Acta, 1999, 63: 4037-4051 [doi]

4 Gaillardet J, Dupre B, Louvat P, et al. Global silicate weathering and $\mathrm{CO}_{2}$ consumption rates deduced from the chemistry of large rivers. Chem Geol, 1999, 159: 3-30[1doi]

5 Kump L R, Brantley S L, Arthur M A. Chemical weathering, atmospheric $\mathrm{CO}_{2}$ and climate. Annu Rev Earth Planet Sci, 2000, 28: $611-667 \underline{\text { [doi] }}$

6 Singh M, Sharma M, Jürgen H, et al. Weathering of the Ganga alluvial plain, northern India: Implications from fluvial geochemistry of the Gomati River. Appl Geochem, 2005, 20: 1-21 $\underline{\text { [doi] }}$

7 Wang B. The Asian Monsoon. London: Springer, 2006

8 姚政权, 郭正堂, 陈宇坤, 等. 渤海湾海陆交互相沉积的磁性地层学. 海洋地质与第四纪地质, 2006, 26: 9-15

9 Cande S C, Kent D V. Revised calibration of geomagnetic polarity time scale for the Late Cretaceous and Cenozoic. J Geophys Res, 1995, 100: 6093-6095[ [doi]

10 陈宇坤, 李振海, 邵永新, 等. 天津地区第四纪年代地层剖面研究. 地震地质, 2008, 30: 383-399

11 McLennan S M. Rare earth elements in sedimentary rocks: Influence of provenance and sedimentary processes. Rev Mineral, 1989, 21: $169-200$

12 Loring D H, Asmund G. Geochemical factors controlling accumulation of major and trace elements in Greenland coastal and fjord sediments. Environ Geol, 1996, 28: 1-11

13 Wei G J, Li X H, Liu Y, et al. Geochemical record of chemical weathering and monsoon climate change since the early Miocene in the South China Sea. Paleoceanography, 2006, 21: 1-11 
14 Nesbitt H W, Markovics G, Price R C. Chemical processes affecting alkalis and alkaline earths during continental weathering. Geochim Cosmochim Acta, 1980, 44: 1659-1666[doi]

15 Taylor S R, McLennan S M. The Continental Crust: Its Composition and Evolution. New York: Oxford, 1985

16 Nesbitt H W, Young G M. Early Proterozoic climates and plate motions inferred from major element chemistry of lutites. Nature, 1982, 299: 715-717 [10i]

17 Nesbitt H W, Young G M. Petrogenesis of sediments in the absence of chemical weathering: Effects of abrasion and sorting on bulk composition and mineralogy. Sedimentology, 1996, 43: 341-358[doi]

18 Young G M. Geochemical investigation of a Neoproterozoic glacial unit: The mineral fork formation in the Wasatch Range, Utah. GSA Bull, 2002, 114: 387-399 [doi]

19 Nesbitt H W, Markovics G. Weathering of granodioritic crust, long-term storage of elements in weathering profiles, and petrogenesis of siliciclastic sediments. Geochim Cosmochim Acta, 1997, 61: 1653-1670[doi]

20 陈骏, 安芷生, 刘连文, 等. 最近 $2.5 \mathrm{Ma}$ 以来黄土高原风尘化学组织的变化与亚洲内陆的化学风化. 中国科学 D辑: 地球科 学, 2001, 31: 136-145

21 Mix A C, Le J, Shackleton N J. Benthic foraminiferal stable isotope stratigraphy of Site 846: 0-1.8 Ma. Proc ODP Sci Results, 1995, 138: $839-854$

22 Shackleton N J, Hall M A, Pate D. Pliocene stable isotope stratigraphy of site 846. Proc ODP Sci Results, 1995, 138: 337 - 355

23 Fralick P W, Kronberg B I. Geochemical discrimination of elastic sedimentary rock sources. Sediment Geol, 1997, 113: 111-124[doi]

24 Johnsson M J. The system controlling the composition of clastic sediments. In: Johnsson M J, Basu A, eds. Processes Controlling the Composition of Clastic Sediments. Colorado: Geological Society of America, 1993

25 Zhang C S, Wang L J, Li G S, et al. Grain size effect on multi-element concentrations in sediments from the intertidal flats of Bohai Bay, China. Appl Geochem, 2002, 17: 59-68[1]

26 Wu C, Xu Q H, Ma Y H, et al. Palaeochannels on the North China Plain: Palaeoriver geomorphology. Geomorphology, 1996, 18: $37-45$ [doi]

27 Yang S Y, Li C X, Cai J G. Geochemical compositions of core sediments in eastern China: Implication for Late Cenozoic palaeoenvironmental changes. Palaeogeogr Palaeoclimatol Palaeoecol, 2006, 229: 287-302 [doi]

28 Zheng H B, Powell C, An Z S, et al. Pliocene uplift of the northern Tibetan Plateau. Geology, 2000, 28: 715-718 [doi]

29 Wang Z Y, Liang Z Y. Dynamic characteristics of the Yellow River mouth. Earth Surf Process Landf, 2000, 25: 765-782[doi]

30 White A F, Blum A E. Effects of climate on chemical weathering in watersheds. Geochim Cosmochim Acta, 1995, 59: 1729$1747 \underline{\text { [doi] }}$

31 Guo Z T, Peng S Z, Hao Q Z, et al. Lat Miocene-Pliocene development of Asian aridification as recorded in the Red-Earth Formation in northern China. Glob Planet Change, 2004, 41: 135-145[ [doi]

32 Huntington K W, Blythe A E, Hodges K V, et al. Climate change and Late Pliocene acceleration of erosion in the Himalaya. Earth Planet Sci Lett, 2006, 252: 107-118 [doi]

33 Zhang P Z, Molnar P, Downs W R. Increased sedimentation rates and grain sizes 2-4 Myr ago due to the influence of climate change

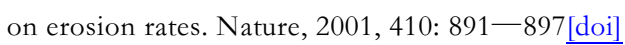

